\title{
VARIAÇÃO TEMPORAL DA TEMPERATURA DE SUPERFÍCIE DA ÁREA URBANA E DOS PARQUES DA CIDADE DE SÃO CARLOS - SP
}

\author{
TEMPORAL VARIATION OF THE SURFACE TEMPERATURE OF THE URBAN AREA \\ AND PARKS IN THE CITY OF SÃO CARLOS - SP
}

Kariele Ferreira da Silva ${ }^{1}$, Camila Tavares Pereira ${ }^{2}$, Renata Bovo Peres ${ }^{3}$

\section{RESUMO}

Os processos de produção das cidades vêm gerando consequências nas condições climáticas, nos quais os espaços livres vegetados são apontados como estratégias positivas para adaptação e mitigação. Reconhecendo a baixa qualidade dos espaços livres em São Carlos (SP), a gestão pública criou um conjunto de Parques Urbanos. O objetivo deste trabalho é analisar a variação da Temperatura de Superfície (TS) em 16 anos (2004 e 2020), em quatro categorias dos Parques Urbanos. A metodologia baseou-se em análises de imagens de satélite LANDSAT 5 (2004) e LANDSAT 8 (2020). A TS foi estimada por meio do complemento Land Surface Temperature Plugin do software QGIS 2.8.9. Considerando todo o território dentro do perímetro urbano, os resultados mostraram um aumento significativo da TS, com elevação de $1,6^{\circ} \mathrm{C}$ da TS média, de 2004 para 2020 . Em ambos os anos, os picos de TS estão presentes em áreas que possuem mais espaços construídos e menos vegetação. As áreas dos Parques Urbanos foram as que apresentaram menores TS. Isso evidencia a importância de um Sistema de Parques e Espaços Livres para o equilíbrio térmico, com produção de informações sistematizadas e contínuas para tomada de decisões relativas ao planejamento e gestão de novos espaços verdes nas cidades.

Palavras-chave: Clima urbano; Sistema de espaços livres; Planejamento urbano; Equilíbrio térmico; Análise temporal.

\begin{abstract}
The production processes of cities have been generating severe consequences in climatic conditions, in which open vegetated spaces are pointed out as adaptation and mitigation strategies. Recognizing the low quality of open spaces in São Carlos (SP), public management has created a set of Urban Parks. The objective of this study is to analyze the variation of the Surface Temperature (ST), in 16 years (2004 and 2020), related to four Urbans Parks categories. The methodology has been based on the analysis of satellite images LANDSAT 5 (2004) and LANDSAT 8 (2020). ST was estimated using the Land Surface Temperature Plugin in QGIS 2.8.9 software. Considering the entire urban area, the results have shown a significant increase in ST, with an average ST increase of $1.6^{\circ} \mathrm{C}$ from 2004 to 2020 . In both years, the ST peaks are present in regions that have more buildings and less vegetation. The Park areas have presented the lowest ST. This conclusion highlights the importance of a System of Parks and Open Spaces for the thermal balance, with the production of systematic and continuous information for decision-making related to the new green areas planning and management in cities.
\end{abstract}

Keywords: Urban climate; Open space system; Urban planning; Thermal balance; Temporal analysis.

Recebido em 21.12.2020 e aceito em 03.08.2021

1 Gestora e Analista Ambiental. Graduada. Universidade Federal de São Carlos. São Carlos/SP. Email: karielleferreira@gmail.com

2.Geógrafa. Doutora em Ciências Ambientais. Universidade Federal de São Carlos. São Carlos/SP. Email: tavares.camila88@gmail.com

3 Arquiteta e Urbanista. Doutora em Engenharia Urbana. Professora Associada do Departamento de Ciências Ambientais. Universidade Federal de São Carlos. São Carlos/SP. Email: renataperes@ufscar.br 


\section{INTRODUÇÃO}

Os processos de produção das cidades brasileiras, historicamente, pouco consideraram os elementos naturais no planejamento, criaram espaços altamente impermeabilizados, rios canalizados, alterações no relevo e retirada da vegetação. Os efeitos desses processos, somados às alterações climáticas, vêm gerando graves consequências, como inundações, deslizamentos, poluição atmosférica, formação de ilhas de calor etc.

Estudos mostram que a vegetação e os espaços verdes podem contribuir para a qualidade urbana e condições de vida da população, proporcionando, entre outros benefícios, sombreamento e esfriamento da temperatura, pelo processo de evapotranspiração. Yu et al. (2017) analisam que o efeito do resfriamento dos espaços verdes é um serviço essencial para mitigar o efeito da ilha de calor urbana. Brown et al. (2015) sugerem que as cidades desenvolvam projetos de parques, pois esses espaços livres têm potencial de fornecer ambientes termicamente confortáveis e ajudar a reduzir a vulnerabilidade ao estresse térmico e as ameaças das ondas de calor.

Para compreender como as áreas verdes proporcionam a amenização da temperatura, alguns métodos e variáveis podem ser utilizados, como a Temperatura de Superfície (TS). A TS analisa os fluxos de calor de um determinado objeto ou espaço, sendo considerado um importante parâmetro para o entendimento das interações entre a superfície terrestre e a atmosfera.

No Brasil, estudos envolvendo a relação entre a presença da vegetação e a Temperatura de Superfície (TS) vêm sendo cada vez mais realizados, apresentando resultados e contribuições às pesquisas termais dos ambientes urbanos e suas dinâmicas. Ferreira (2019) analisou os efeitos da perda da cobertura vegetal sobre o meio ambiente e a qualidade de vida da população na Região Metropolitana de São Paulo (SP). Estudando as relações entre vegetação, TS e morfologia urbana, verificou que áreas com presença de vegetação apresentam menores temperaturas ao longo de todo o ano.

Pereira, Lima e Bourscheidt (2017) avaliaram a relação entre a distribuição da TS em Santos (SP), correlacionando com dados socioeconômicos. Verificaram que bairros com renda salarial menor apresentam maior TS do que os bairros mais ricos, próximos à orla. A relação é explicada devido a maior ausência de vegetação e áreas verdes, maior densidade demográfica e impermeabilização do solo.

Feitosa et al. (2011) verificaram a relação entre a expansão urbana de Teresina (PI) com a supressão da vegetação. Em um período de 20 anos (1989 a 2009) houve perda de quase $30 \%$ da vegetação dentro do perímetro urbano. A expansão de áreas de superfícies aquecidas influenciou o aumento da temperatura do ar e alterou o comportamento 
microclimático da cidade. Os autores sugerem a conservação de áreas vegetadas e de reservatórios de água que contribuem para a manutenção da umidade do ar, como forma de reduzir os efeitos causados pelas mudanças no clima e proporcionar melhor conforto à população.

Callejas et al. (2011) também estudaram, em Várzea Grande (MT), a relação espaçotemporal entre o uso da terra e a TS, entre os anos de 1986 e 2007. Os resultados demonstram que os maiores valores de TS foram encontrados em solos expostos e áreas construídas, com ênfase em um aumento de mais de $2,13^{\circ} \mathrm{C}$ em média, das temperaturas superficiais nas áreas de baixa e densa urbanização. $O$ estudo recomendou a realização de ações que visem preservar a vegetação remanescente e implantar novas áreas verdes em posições estratégicas na cidade.

Pensando justamente na implantação de parques em áreas estratégicas e reconhecendo a necessidade de melhor distribuição e qualidade dos espaços verdes, o município de São Carlos (SP), promoveu a criação de sete Parques Urbanos em diferentes regiões da cidade (SÃO CARLOS, 2017). Essas áreas são de domínio público, dispõem de significativos fragmentos de vegetação e apresentam distintos potenciais.

Em escala intraurbana, estudos realizados por Viana (2013) e Bertini et al. (2016) demonstram que $26 \%$ da área urbana são cobertos por vegetação arbórea, porém a distribuição no território é irregular e desigual. Rampazzo (2015) identificou regiões de São Carlos com formação de ilhas de calor de alta intensidade, com diferenças de temperatura superiores a $7^{\circ} \mathrm{C}$. Tais regiões estão relacionadas a locais densamente edificados e pouco arborizados.

A partir da criação dos sete Parques Urbanos (que totalizou 225,65 hectares de áreas demarcadas e protegidas), o Grupo de Trabalho de Planejamento dos Parques Urbanos GTPU estendeu a proposta para a constituição de um Sistema de Parques e Espaços Livres, envolvendo a proposição de três categorias de Parques: Parques Urbanos, Parques Lineares e Parques de Conservação (ampliando a proteção para cerca de 3 mil hectares) de espaços de múltiplas finalidades.

Diante do exposto, e partindo das categorias dos Parques Urbanos criados para o município, o objetivo deste trabalho foi realizar uma análise da variação da Temperatura de Superfície (TS), em um período de 16 anos (de 2004 a 2020), relacionando a presença de quatro categorias de Parques na cidade de São Carlos (SP).

Espera-se com isso, contribuir com a discussão científica sobre a importância dos Parques Urbanos e do Sistema de Espaços Livres para o controle da temperatura e para o equilíbrio do clima nas cidades. 


\section{MATERIAL E MÉTODOS}

\section{1 Área de Estudo}

São Carlos configura-se como uma cidade média paulista de relevância regional, localizada na porção centro-oeste do Estado de São Paulo (Figura 1). Possui uma extensão territorial de 1.136,9 $\mathrm{Km}^{2}$, população estimada de 254.484 habitantes e densidade demográfica de 195,15 habitantes por $\mathrm{Km}^{2}$ (IBGE, 2020). Além do critério populacional, os fatores que a caracterizam como uma cidade média de referência são: seu papel produtivo; sua articulação na rede urbana, localização em eixos de desenvolvimento; presença de universidades, tecnopólos e centros de pesquisas, o que a torna uma cidade conectada com redes globais de conhecimento e de inovação (SPOSITO; GÓES, 2013).

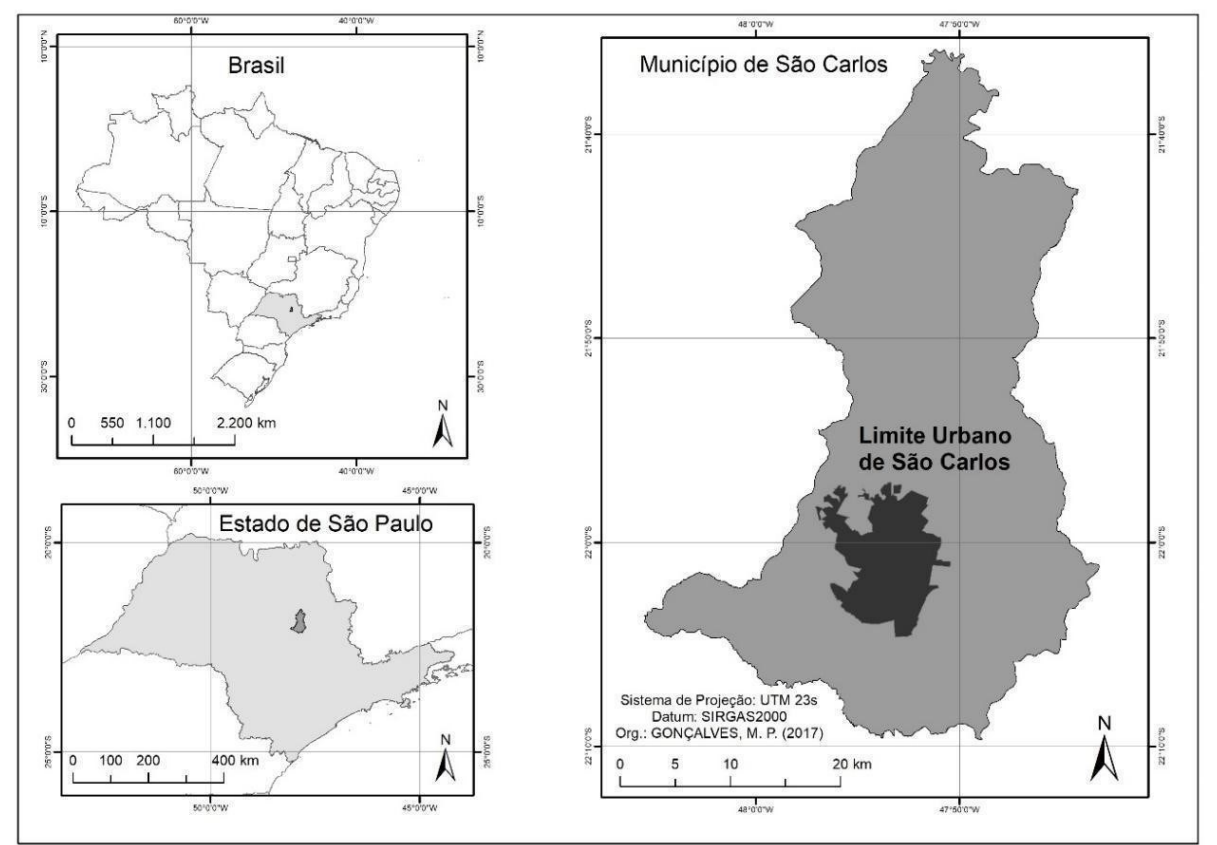

Figura 1. Localização do município de São Carlos (SP).

Fonte: GONÇALVES (2018).

Figure 1. Location of the municipality of São Carlos (SP).

O município encontra-se na região geomorfológica das Cuestas Basálticas que se caracterizam, morfologicamente, por apresentar relevos acentuados e escarpados (IPT, 2015). A altimetria varia de 630 metros em fundos de vale, chegando a 945 metros em alguns bairros da malha urbana e, até 1015 metros, em pontos no entorno da cidade. A declividade apresenta percentual médio de 10 a 30\%. No limite sul da malha urbana chega a índices maiores a $45 \%$. O contexto geológico também favorece a ocorrência de áreas de risco de deslizamentos localizadas, sobretudo, em regiões de solos arenosos da Formação Botucatu e da Formação 
Serra Geral (IPT, 2015).

Em relação à cobertura vegetal, embora a proporção seja considerada relevante para a totalidade da área urbana, chegando a 26\% (VIANA, 2013), estes índices são mal distribuídos entre os lugares da cidade. Bertini et al. (2016) calcularam o Índice de Áreas Verdes Públicas (IAV) para São Carlos, no ano de 2016, e identificaram que este atingiu $18,85 \mathrm{~m}^{2}$ por habitante. Contudo, destacaram valores discrepantes entre diferentes regiões da cidade, que variaram de $4 \mathrm{~m}^{2} /$ habitante até $36 \mathrm{~m}^{2} /$ habitante. Viana (2013) também evidenciou a distribuição espacial desigual, irregularidade de cobertura vegetal, distribuição e baixa qualificação das áreas verdes e espaços livres públicos no espaço urbano de São Carlos.

Os Parques Urbanos, que foram criados pelo Decreto $n^{\circ} 170 / 2017$, são áreas de domínio público, já dispõem de significativos fragmentos de vegetação, além de apresentarem características e funções distintas. Como desdobramentos do processo de criação destes Parques, o Grupo de Trabalho de Planejamento dos Parques Urbanos - GTPU construiu um movimento na direção da elaboração de diretrizes para um Sistema de Parques e Espaços Livres para São Carlos (Figura 2). A ação buscou articular os Parques do Decreto a um potencial sistema que reúne rede hídrica, áreas protegidas por legislação ambiental e reservas legais periurbanas, áreas verdes públicas, bem como o sistema de mobilidade.

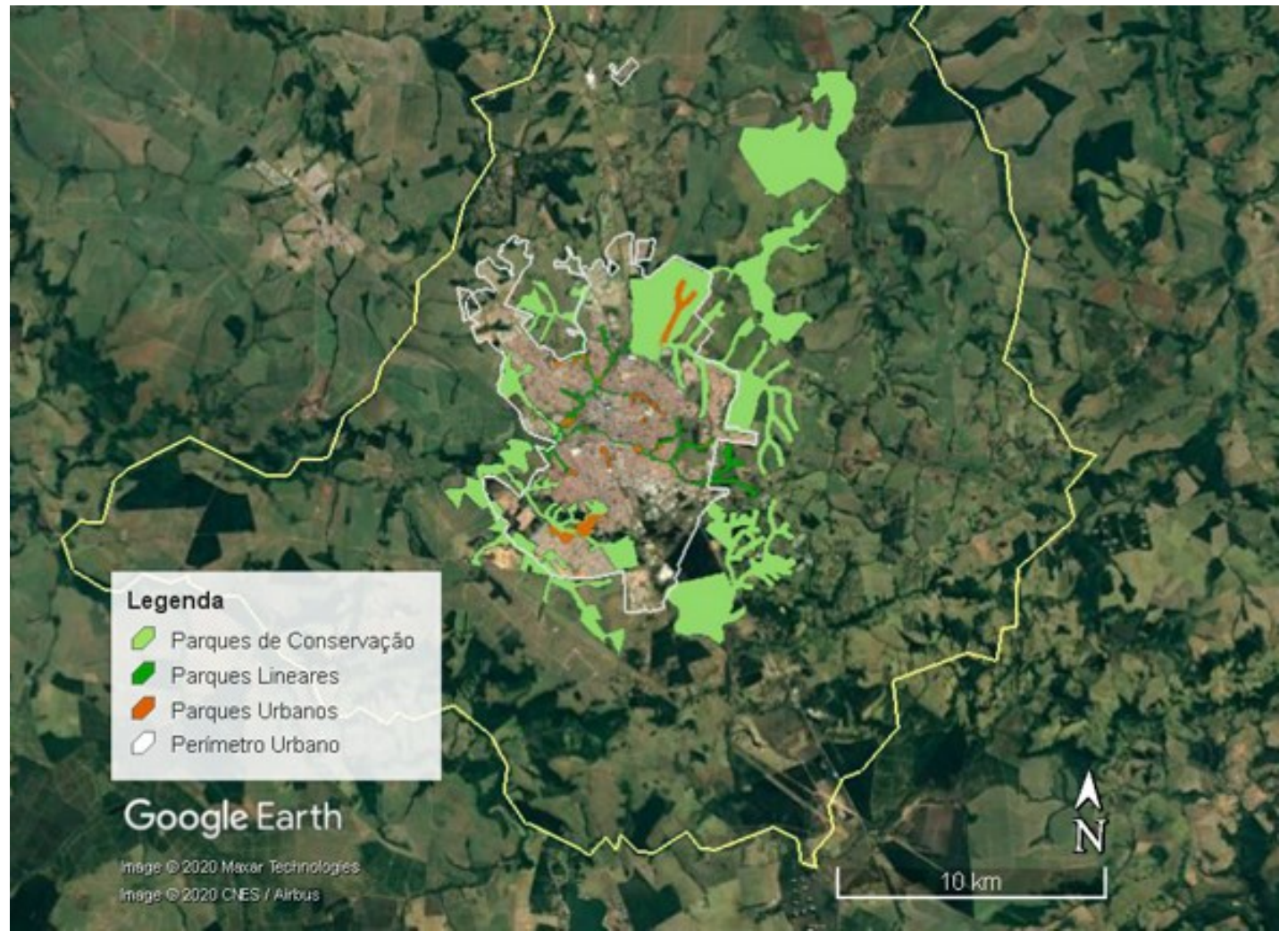

Fonte: Os Autores adaptado de GTPU.

Figura 2. Proposta do Sistema de Parques e Espaços Livres para São Carlos (SP).

Figure 2. Proposal for the System of Parks and Open Spaces of São Carlos (SP). 


\subsection{Imagens do LANDSAT}

Para as análises espaciais foram utilizadas imagens do satélite LANDSAT 5 (de 19 de janeiro de 2004) e LANDSAT 8 (de 15 de janeiro de 2020), ambos com órbita 220 e ponto 75 . A primeira imagem foi obtida às 12:48 GTM e a segunda às 13:10 GTM. Por meio do complemento Semi-Automatic Classification Plugin (CONGEDO, 2016), as bandas $1-5$ do LANDSAT 5 e as bandas $2-7$ do LANDSAT 8 passaram por correção atmosférica simples (DOS1).

Os dias escolhidos são, de acordo com Oke et al. (2017), os mais representativos para analisar a temperatura de superfície, neste caso, dias com pouca ou nenhuma nuvem. Nas imagens de satélite utilizadas no trabalho, ambas têm menos que $10 \%$ de nuvens e nenhuma nuvem sob a área de estudo, ventos fracos e sem precipitação. Além disso, por meio da Estação Climatológica do CRHEA USP São Carlos, foram conferidos os dados citados acima e a temperatura do ar. Ambos os dias são representativos da média do verão para a área de estudo $\left(+-30^{\circ} \mathrm{C}\right)$.

\subsection{Estimativa da Temperatura de Superfície}

A Temperatura da Superfície (TS) para os dois períodos analisados foi estimada por meio do complemento Land Surface Temperature Plugin (ISAYA NDOSSI e AVDAN, 2016) no software QGIS 2.8.9. O complemento concentra diversos algoritmos que permitem uma série de análises: a conversão de números digitais (ND) em radiância; a conversão da radiância em temperatura de brilho; o cálculo do Índice de Vegetação da Diferença Normalizada - NDVI; a estimativa da emissividade da superfície; e a extração da TS pela função de Planck, pela Equação de Transferência Radiativa (RTE), pelo algoritmo de canal único e pelo algoritmo Mono-Window.

No presente trabalho, o cálculo da temperatura de superfície pelo complemento consistiu na execução das etapas apresentadas na Figura 3. Entre as opções para a estimativa da emissividade da superfície, optou-se pela utilização do algoritmo com base na imagem NDVI ("Zang, Wang etal's LSE algorithm"), visto que a aplicação desse índice apresenta resultados mais realistas e precisos (ISAYA NDOSSI e AVDAN, 2016). Para a estimativa da TS utilizou-se o algoritmo Planck. Segundo estudo realizado por Isaya Ndossi e Advan (2016), em Toronto, os algoritmos que apresentam a menor raiz quadrada do erro quadrático médio (em inglês, Root Mean Square Error) são a equação de Planck e a RTE. Contudo, este primeiro procedimento pode subestimar a temperatura de superfície, apesar de ser mais fácil sua 
aplicação por não utilizar dados meteorológicos.

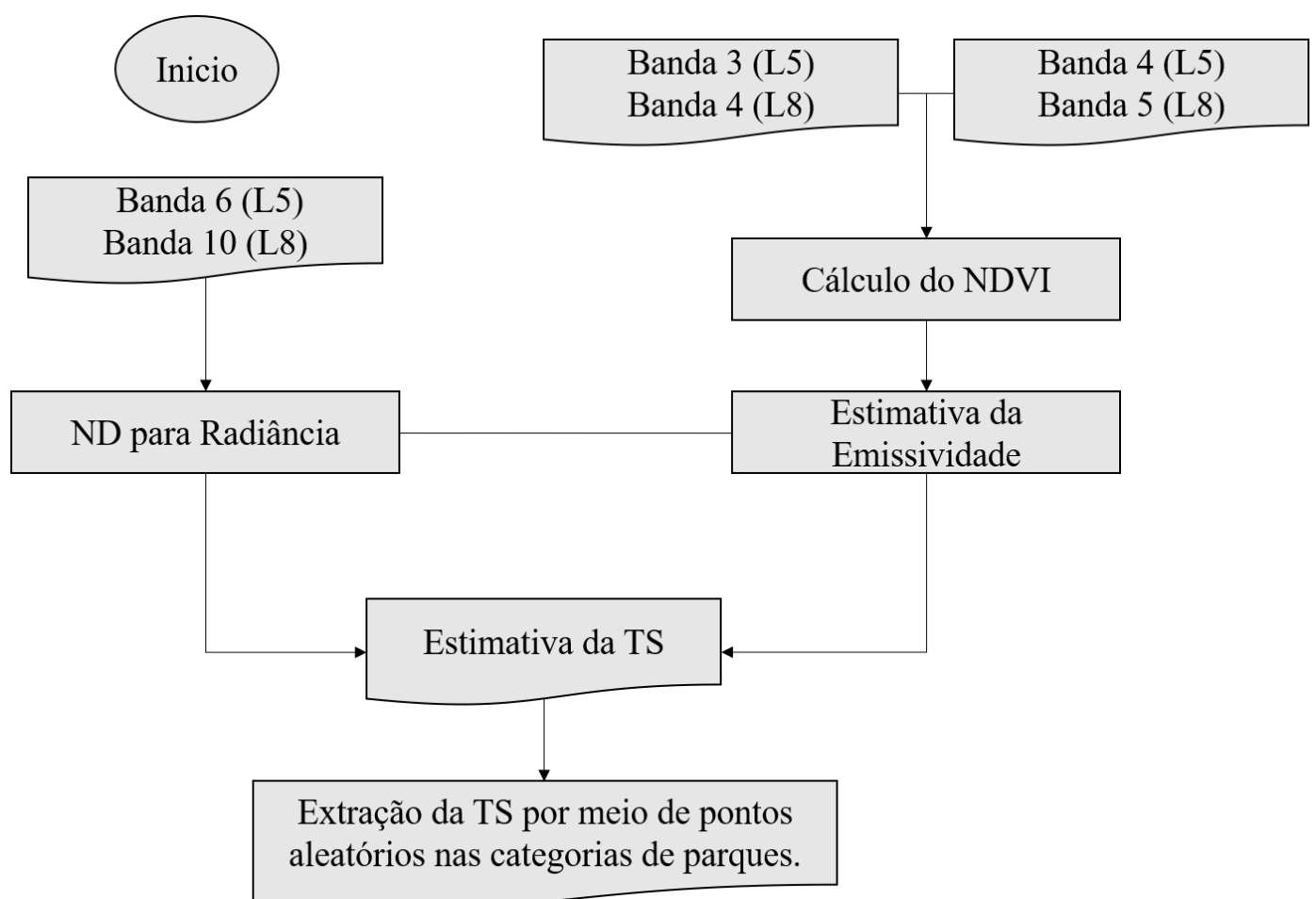

Figura 3. Fluxograma das etapas realizadas no Land Surface Temperature Plugin para estimativa da Temperatura de Superfície (TS).

Figure 3. Flowchart of the steps performed in the Land Surface Temperature Plugin to estimate the Surface Temperature (ST).

\subsection{Seleção dos Parques para análise da Temperatura de Superfície}

Tomando como referência a proposta geral do Sistema de Parques e Espaços Livres para a cidade de São Carlos, realizado pelo GTPU, o trabalho focou a análise na relação da TS com os Parques existentes dentro do perímetro urbano (Figura 4). Nesse recorte territorial, os Parques foram divididos em quatro categorias: Parques Lineares, Parques Urbanos do Decreto, Parques Urbanos Existentes e Parques Urbanos Potenciais.

Os Parques Lineares são espaços distribuídos por toda a cidade e apresentam configuração atrelada principalmente aos cursos d'água, mas também a vias e ferrovias. Possuem fragmentos de vegetação significativos ou em recuperação, e representam, sobretudo, as Áreas de Preservação Permanentes (APPs) ao longo dos fundos de vale dos córregos ou áreas adjacentes. A sua principal função é a conectividade dos espaços verdes e das pessoas. Constituem um dos elos do Sistema de Espaços Livres, podendo estar agregados à outras categorias de Parques. Funcionam como corredores verdes e de circulação de ar e, portanto, estão associados ao controle do microclima. Possuem também uma função 
ecológica, de proteção das APPs, associadas à drenagem natural, podendo proteger a população de enchentes e deslizamentos. Podem incluir ciclovias, vias arborizadas, equipamentos de lazer e esportes, percursos e lugares de convívio e estar.

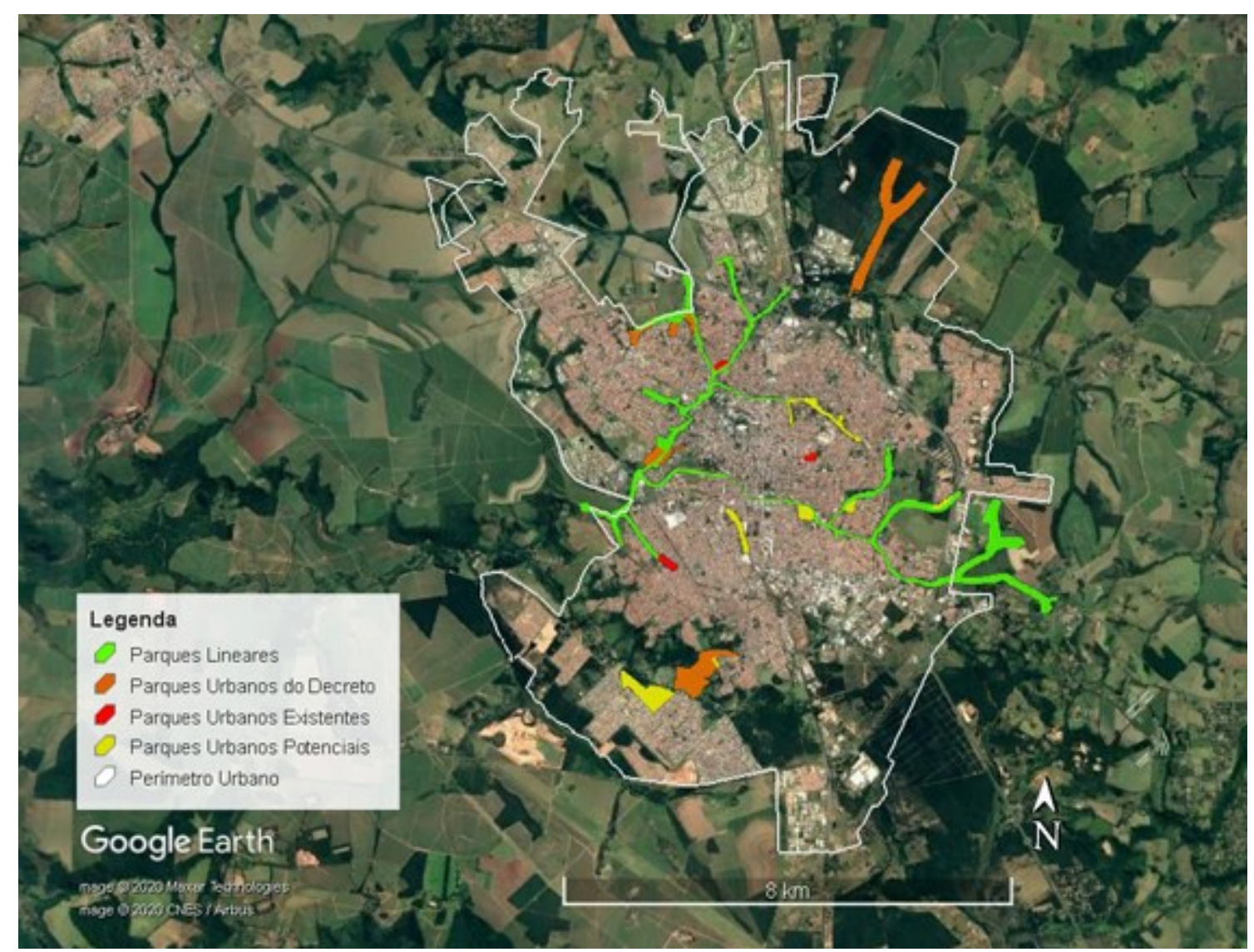

Fonte: Os Autores adaptado de GTPU.

Figura 4. Proposta do Sistema de Parques e Espaços Livres, com destaque para os Parques Lineares e Parques Urbanos de São Carlos (SP).

Figure 4. Proposal for the System of Parks and Open Spaces, with emphasis on the Linear Parks and Urban Parks of São Carlos (SP).

Os Parques Urbanos são áreas públicas mais consolidadas e antropizadas, distribuídos por toda a cidade, podendo apresentar vegetação densa ou dispersa. São espaços multifuncionais, geralmente mais delimitados e integrados aos Parques Lineares. Os usos estão ligados ao lazer, descanso, recreação, eventos culturais e educativos. Os Parques Urbanos subdividem-se em três categorias. A primeira categoria são os Parques Urbanos publicados pelo Decreto de 2017, que são espaços verdes já existentes, porém ainda com necessidade de melhorias estruturais. As finalidades dos Parques do Decreto são: 1) proteção dos remanescentes da Mata Atlântica e Cerrado com o objetivo de assegurar a manutenção dos processos ecológicos; 2) realização de pesquisa científica e capacitação técnica visando orientar a proteção de remanescentes de vegetação nativa em áreas urbanas e periurbanas e 
a formação de corredores regionais de biodiversidade; 3) realização de atividades de educação ambiental visando difundir conceitos e estimular a adoção de práticas para a conservação ambiental e o uso sustentável de recursos naturais; e 4) uso público para atividades culturais e educacionais, recreação e lazer.

A segunda categoria são os Parques Urbanos Existentes, que se referem aos três parques já existentes antes do Decreto de 2017 e são muito utilizados pela população (Parque do Kartódromo, Parque do Bicão e Campo do Rui), com usos mais consolidados, equipamentos de lazer e tratamento paisagístico. A terceira categoria refere-se aos Parques Urbanos Potenciais, que são espaços livres ainda sem uso e à espera de qualificação.

\section{RESULTADOS E DISCUSSÕES}

\subsection{Análise da Temperatura de Superfície no perímetro urbano de São Carlos (SP)}

Considerando toda a extensão do perímetro urbano de São Carlos, ao longo dos últimos 16 anos (2004 a 2020), observa-se um aumento da temperatura de superfície, que pode atingir temperaturas de $36^{\circ} \mathrm{C}$ a $40^{\circ} \mathrm{C}$, com maior evidência nas regiões central e sul da cidade (Figura 5).

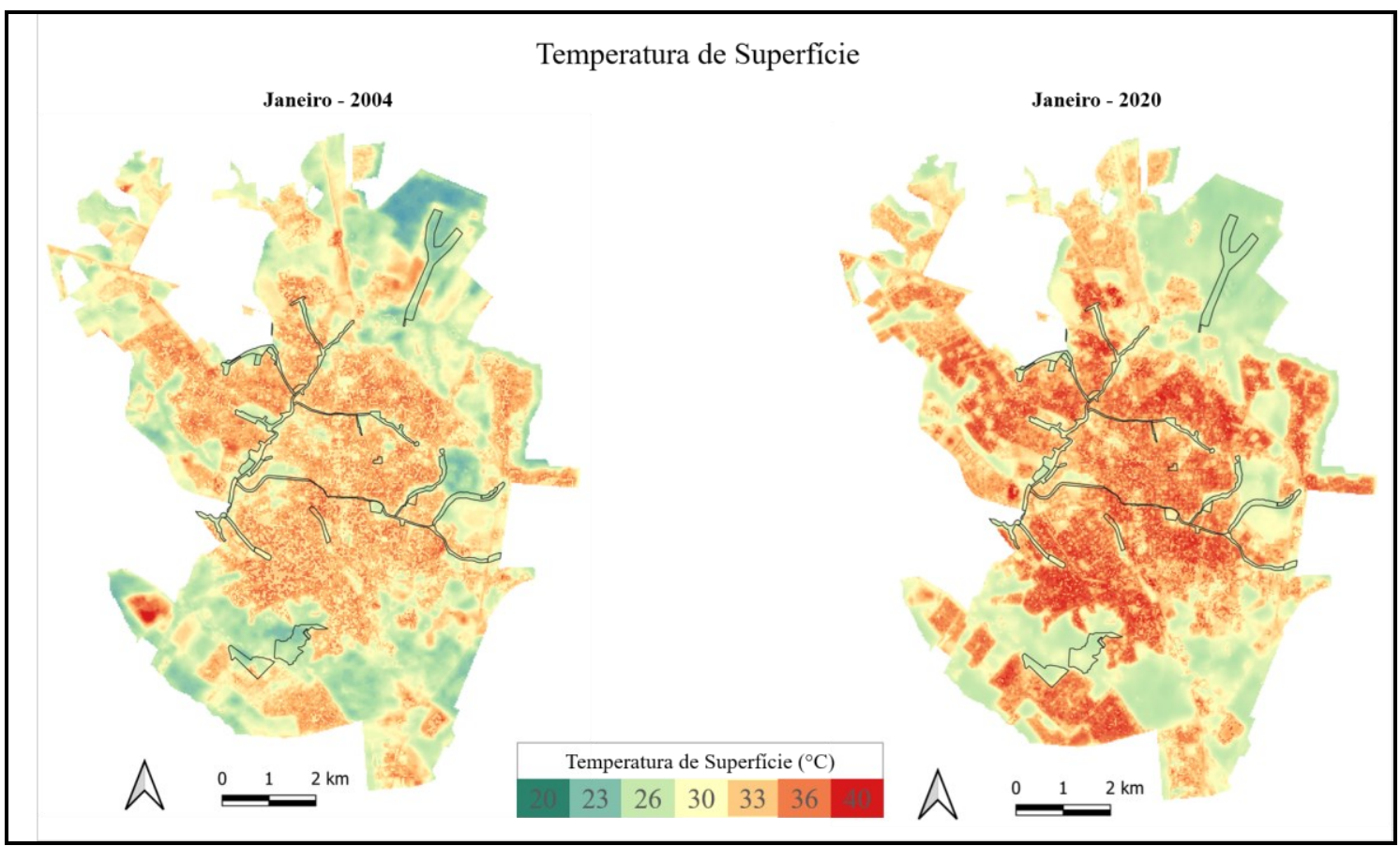

Figura 5. Temperatura de Superfície (TS) no perímetro urbano de São Carlos (SP), com destaque para as áreas delimitadas de Parques Urbanos e Lineares.

Figure 5. Surface Temperature (ST) in the urban perimeter of São Carlos (SP), with emphasis on the delimited areas of Urban and Linear Parks. 
A partir da imagem de 19 de janeiro de 2004, a temperatura média da área dentro do perímetro urbano foi de $30,4^{\circ} \mathrm{C}$, com registro mínimo de $21,5^{\circ}$ e máximo de $38,4^{\circ} \mathrm{C}$ e desvio de padrão de $3,5^{\circ} \mathrm{C}$. Para o ano de 2020 (na imagem de 15 de janeiro), houve um aumento de aproximadamente $2^{\circ} \mathrm{C}$ em todas as temperaturas estimadas (Tabela 1).

Tabela 1. TS para o perímetro urbano de São Carlos (SP).

Table 1. Surface temperature for the urban perimeter of São Carlos (SP).

\begin{tabular}{lcc}
\hline Temperatura de Superfície $\left({ }^{\circ} \mathbf{C}\right)$ & $\mathbf{2 0 0 4}$ & $\mathbf{2 0 2 0}$ \\
\hline Máxima & 38,4 & 39,0 \\
Média & 30,4 & 32,0 \\
Mínima & 21,5 & 24,0 \\
Desvio padrão & 3,5 & 3,7 \\
\hline
\end{tabular}

A TS máxima encontrada dentro do perímetro urbano de São Carlos em 2004 foi de $38,4^{\circ} \mathrm{C}$, enquanto a mínima equivale a $21,5^{\circ} \mathrm{C}$. No entanto, para o ano de 2020 , a TS máxima encontrada foi de $39,0^{\circ} \mathrm{C}$, e a mínima de $24,0^{\circ} \mathrm{C}$. Comparando o ano de $2004 \mathrm{com} 2020$, a TS média aumentou e a amplitude térmica diminuiu. Sendo que a TS média apresentou um aumento de $1,6^{\circ} \mathrm{C}$, enquanto que a amplitude térmica obteve uma queda de apenas $0,5^{\circ} \mathrm{C}$ para o período em análise. Isso significa que as áreas estão cada vez mais homogêneas e essa homogeneidade de TS está relacionada a estrutura térmica que aquece cada vez mais a cidade devido à expansão urbana.

Os acréscimos da TS no período analisado estão relacionados com o aumento de áreas de intensa emitância termal, como edifícios, pavimentos, asfalto, telhados e outras superfícies típicas impermeabilizadas na paisagem urbana. O aumento de impermeabilização em áreas já consolidadas, somadas à urbanização em novas áreas, sobretudo nas bordas do perímetro urbano, contribuíram para o aquecimento da cidade.

Em duas áreas limítrofes do perímetro urbano, uma ao Norte e outra ao Sul da cidade de São Carlos, observa-se menores TS. Estas estão associadas a regiões com presença de grandes fragmentos de vegetação e alguns Parques Urbanos. Ao Norte encontra-se a área de preservação de Cerrado da Universidade Federal de São Carlos (UFSCar). Ao Sul destaca-se a região dos fragmentos florestais da Bacia Hidrográfica do Água Quente e do Parque Florestal Urbano da Serrinha do Aracy. Contudo, mesmo nestes espaços, a temperatura mínima, que era de aproximadamente $22^{\circ} \mathrm{C}$ em 2004 , aumentou para $24^{\circ} \mathrm{C}$, chegando até $26^{\circ} \mathrm{C}$, devido ao aumento da impermeabilização do entorno.

As respostas térmicas obtidas pelas imagens do Landsat para a área de estudo 
corroboram com outras pesquisas que utilizaram métodos semelhantes, como outros satélites, em áreas de intensa urbanização. No trabalho realizado por Ferreira (2019) na Região Metropolitana de São Paulo (RMSP), os resultados encontrados evidenciam que mesmo no período noturno (01:30h) as TS mais elevadas se concentram na região central, em contraste com as menores temperaturas em áreas que apresentam maior cobertura vegetal.

Araujo et al. (2010) estimam, mediante dados de imagens do Landsat 5 de 1990, 1998 e 2003, a TS de Maceió (AL), que nos últimos 30 anos teve seu crescimento intensificado, onde mudanças locais causadas por edificações e ocupações inadequadas provocaram alterações no conforto urbano, e seus resultados mostram que a TS média apresentou os maiores valores em $1998\left(26,96^{\circ} \mathrm{C}\right)$ em comparação com os de $1990\left(24,19^{\circ} \mathrm{C}\right)$ e $2003\left(24,90^{\circ} \mathrm{C}\right)$.

Feitosa et al. (2011), verificaram a relação entre a expansão da cidade com a supressão da vegetação. Utilizaram imagens do satélite Landsat 5, referentes a 1989 e 2009, na análise da supressão decorrente da expansão e na formação do campo térmico para estimar a TS da área urbanizada. Os resultados mostraram que em 1989, a área apresentava TS mais amena. Enquanto em 2009, com o crescimento da urbanização, as áreas verdes diminuíram, aumentando, as áreas aquecidas, assim, indicando que essa situação pode alterar o comportamento do clima.

Pereira, Lima e Bourscheidt (2017), analisando a orla de Santos (SP), utilizaram a imagem do satélite LANDSAT 5 , e observaram resultados próximos de TS média e máxima mais amenas (entre $34^{\circ}$ e $38^{\circ} \mathrm{C}$, respectivamente), devido ao "efeito de sombra" dos grandes edifícios, da brisa marítima e das áreas verdes. Em contraste, observaram um aumento de TS nos bairros de classe média (entre $40^{\circ}$ e $44^{\circ} \mathrm{C}$ ), enquanto que nas regiões em que se concentra a população de baixa renda e maior número de assentamentos informais houve um aumento significativo da TS (máxima entre $44^{\circ}$ e $46^{\circ}$ e média de $42^{\circ} \mathrm{C}$ ). Confirmaram, assim, que as áreas de morros, por conter um espaço de vegetação e estar em maior altitude, apresentam TS média mais amena (entre $34^{\circ}$ e $36^{\circ}$ ).

\subsection{Análise da Temperatura de Superfície nas categorias de Parques do perímetro urbano de São Carlos (SP)}

A fim de observar a resposta térmica dos Parques Urbanos selecionados neste estudo, foram gerados 100 pontos aleatórios em cada categoria: Parques Lineares, Parques do Decreto, Parques Existentes e Parques Potenciais. Também foram gerados 100 pontos para o perímetro urbano de São Carlos para nível de comparação. Os valores obtidos pela extração da TS são apresentados na Figura 6. 


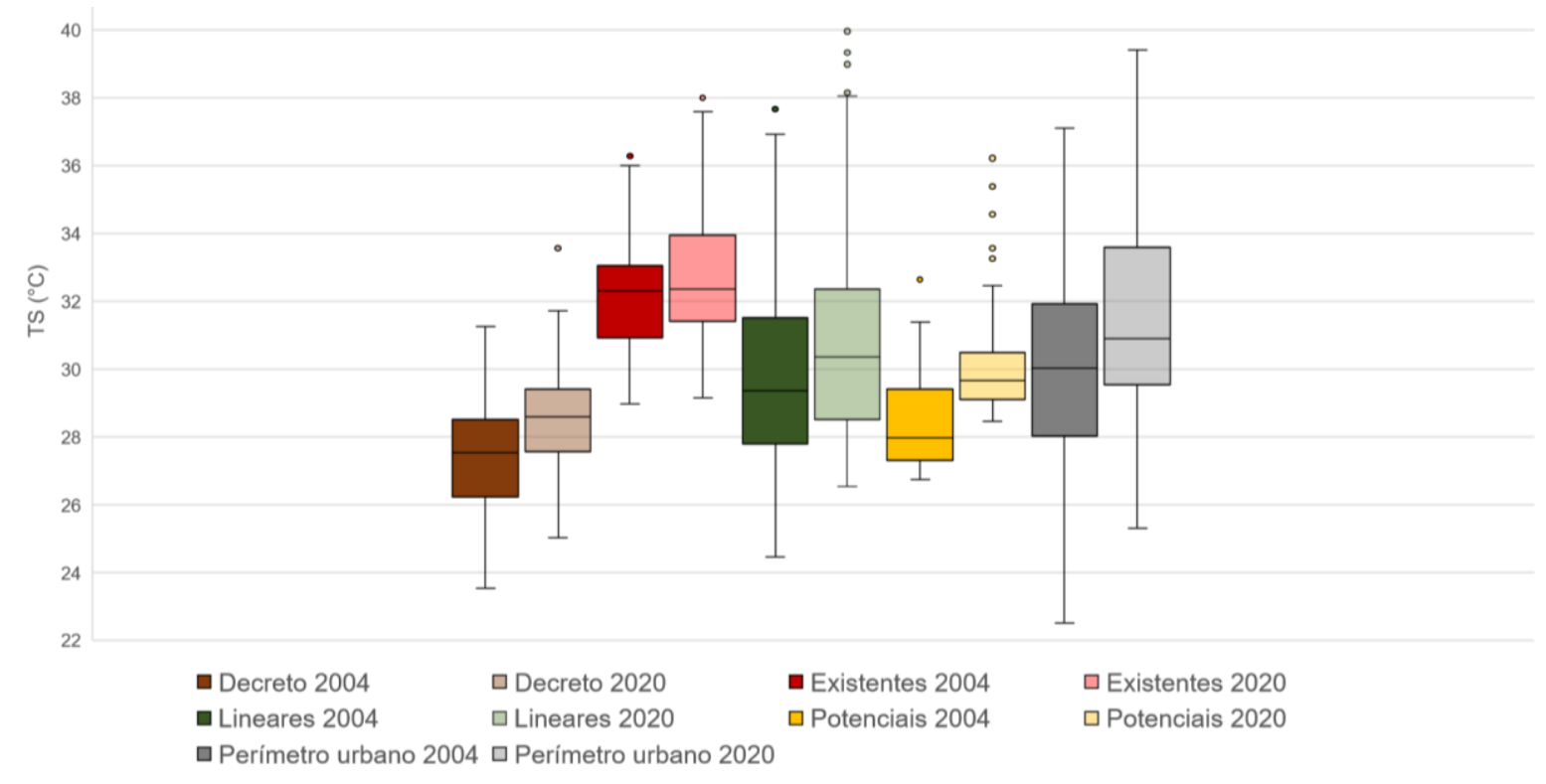

Figura 6. Boxplot com os valores da TS nas categorias de parques e perímetro urbano de São Carlos (SP).

Figure 6. Boxplot with TS values in the park categories and in the urban perimeter of São Carlos (SP).

Os Parques que apresentaram o menor aquecimento e menor amplitude térmica foram os Parques do Decreto; com variação temporal $<2{ }^{\circ} \mathrm{C}$ para todas as temperaturas estimadas. Em 2004, enquanto as TS mínimas para os Parques do Decreto foram de $23,4^{\circ} \mathrm{C}$, as máximas foram de $31,3^{\circ} \mathrm{C}$. Para o ano de 2020 , as TS mínimas foram $25,1^{\circ} \mathrm{C}$, enquanto que as máximas foram $31,7^{\circ} \mathrm{C}$. Considera-se que tal fato deve-se, principalmente, porque os Parques Urbanos do Decreto apresentam áreas com vegetação mais densa em relação às outras categorias de parques analisadas. A Figura 7 apresenta dois Parques do Decreto: à esquerda o Parque Bosque Cambuí e à direita o Parque Dr. Samuel Murgel Branco. A Figura 8 apresenta dois Parques Existentes: à esquerda, o Parque do Kartódromo e, à direita, o Parque do Bicão.
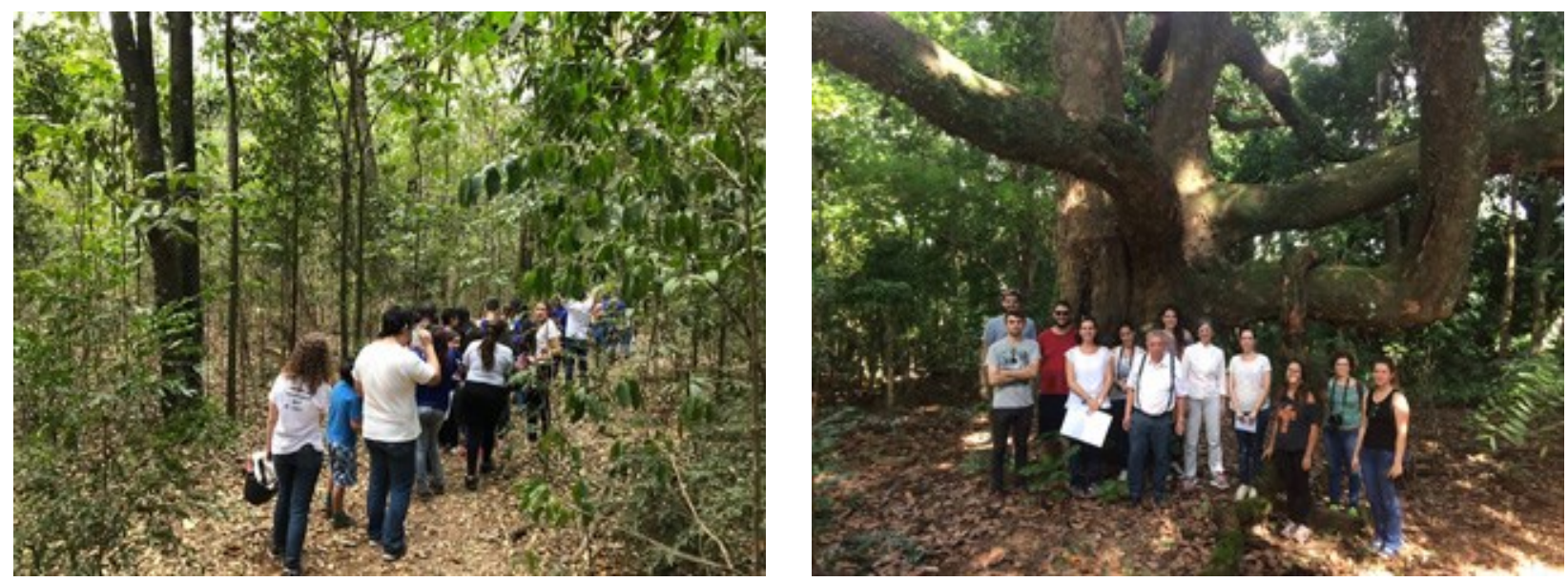

Figura 7. Imagens de dois Parques do Decreto: à esquerda, o Parque Bosque Cambuí e, à direita, o Parque Dr. Samuel Murgel Branco.

Figure 7. Images of two Parks of the Decree: on the left, the Bosque Cambuí Park and, on the right, the 

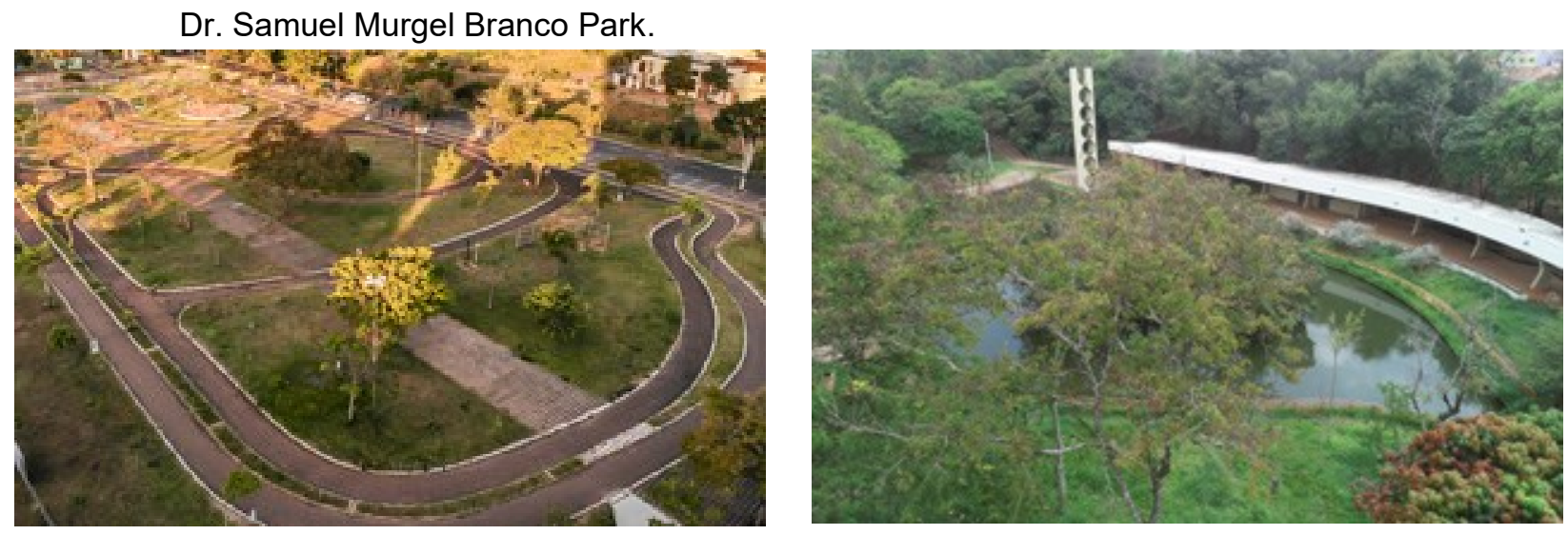

Figura 8. Imagens de dois Parques Existentes: à esquerda, o Parque do Kartódromo e, à direita, o Parque do Bicão.

Figure 8. Images of two Existing Parks: on the left, the Kartódromo Park and, on the right, the Bicão Park.

Os Parques Potenciais também apresentaram baixo aquecimento e amplitude térmica. Em 2004, enquanto as TS mínimas foram de $26,7^{\circ} \mathrm{C}$, as máximas foram de $31,4^{\circ} \mathrm{C}$ (podendo chegar a $32,6^{\circ} \mathrm{C}$ ). Para o ano de 2020 , as TS mínimas foram $28,5^{\circ} \mathrm{C}$, enquanto que as máximas foram $32,5^{\circ} \mathrm{C}$ (podendo chegar a $36,2^{\circ} \mathrm{C}$ ).

Os Parques Existentes, categoria que representa os Parques Urbanos mais utilizados pela população, para lazer e atividades físicas, não tiveram variação temporal nas temperaturas mínimas $\left(29^{\circ} \mathrm{C}\right)$. Em relação às temperaturas máximas, houve um aumento de $1,7^{\circ} \mathrm{C}$ entre o período analisado.

Cabe ressaltar que estes parques, consolidados há mais de 15 anos, são representativos de vegetação mais dispersa, com áreas impermeáveis para caminhadas e demais atividades. Com espaços mais construídos e impermeabilizados proporcionam maior absorção da radiação solar e menor sombreamento, o que favorece o aumento da TS. A Figura 8 apresenta dois Parques Existentes: à esquerda o Parque do Kartódromo e à direita o Parque do Bicão.

Em relação aos Parques Lineares, apesar de estarem atrelados aos cursos hídricos e Áreas de Preservação Permanente, a amplitude térmica $\left(12,4^{\circ} \mathrm{C}\right.$ e $\left.11,7^{\circ} \mathrm{C}\right)$ comprova espaços de configurações urbanas mais heterogêneas e que contribuem para o aquecimento da superfície. Grande parte dos fundos de vales urbanos em São Carlos foram utilizados para a construção de avenidas marginais muito próximas aos rios, resultando em alta impermeabilização do solo, áreas mais edificadas e pouca presença de espaços livres mais permeáveis.

Nessas áreas, o aumento temporal das temperaturas estimadas e a máxima de $38,4^{\circ} \mathrm{C}$ em 2020 (podendo chegar a $40,0^{\circ} \mathrm{C}$ ) é semelhante às TS encontradas para o perímetro urbano de São Carlos, o que evidencia que nesta categoria houve supressão da vegetação. 
No estudo realizado por Silva et al. (2015), determinou-se a TS em uma porção do semiárido da Paraíba, mediante imagens do sensor (TM)/Landsat, com datas de 2004, 2005, 2006 e 2009. Os resultados dos valores médios de TS variaram entre 21,86 e $34,76^{\circ} \mathrm{C}$, de forma geral, as temperaturas mais altas foram obtidas em superfícies com pouca ou nenhuma vegetação, concluindo-se que há uma grande variação térmica entre os diferentes usos do solo.

Em uma pesquisa realizada por Coelho et al. (2013), na qual utilizaram o sensor TIRS/Landsat-8, seus resultados evidenciaram áreas em Vitória (ES) com intensa exitância termal (prédios, pavimentos e telhados), bem como a distribuição heterogênea dessas respostas, resultando em TS com amplitudes elevadas superiores a $12^{\circ} \mathrm{C}$. Constatou-se também a influência e a importância da cobertura vegetal na amenização da temperatura, com os menores valores detectados em superfície de água e manguezal, enquanto as maiores foram identificadas nas áreas construídas.

Utilizando imagens do Thematic Mapper (TM) Landsat 5 para verificar a distribuição espacial da TS, em 2009 e 2010, no município de Humaitá (AM), autores encontraram os maiores valores nas áreas modificadas e os menores valores, na floresta. As áreas de campos e urbana, quando comparadas com florestas, apresentaram na TS um incremento de 3,8 e $10^{\circ} \mathrm{C}$, respectivamente, mostrando um forte impacto nas variáveis físicas locais, quando se altera a cobertura vegetal natural (PAVÃO et al., 2015).

Segundo o trabalho realizado em Guangzhou (China) por Hu e Jia (2010), verificou-se que a fração de cobertura verde apresentou uma correlação negativa com a TS, evidenciando assim um decréscimo de $16,2 \%$ na cobertura arbórea correspondeu a um aumento de 2,48\% na TS.

Alguns estudos que envolvem Temperatura de Superfície destacam a importância relacionada ao uso de imagens e frequência de comparação dos dados. Neste trabalho, os dias escolhidos foram considerados os mais representativos para analisar a TS, pois são dias com pouca ou nenhuma nebulosidade. Há algumas limitações que podem ser aprimoradas em estudos posteriores, tais como: maiores quantidades de comparações entre imagens, condições atmosféricas ou outras variáveis complementares.

Rodrigues et. al. (2017), realizaram um comparativo dos parques urbanos de Goiânia (GO) com ambientes externos em 2013, com coletas de campo para estimar os valores de temperatura e umidade relativa do ar. Constatou-se diferença de temperatura, onde áreas expostas ao sol dentro dos parques possuem temperatura significativamente menores do que comparado às áreas externas, evidenciando-se a importância de áreas verdes no interior das cidades. 
Silva et. al. (2015), avaliaram o impacto de diferentes tipos de distribuição de vegetação inseridos no meio urbano em relação ao conforto térmico, num trecho urbano de Vitória (ES). Os dados encontrados permitiram constatar a influência da vegetação como um forte condicionante, concluindo-se que embora os parques urbanos exerçam influência no conforto do entorno imediato, a distribuição da vegetação na malha urbana tende a trazer melhores resultados.

Desse modo, destaca-se que a criação dos novos Parques Urbanos na cidade de São Carlos, representa uma importante iniciativa ao planejamento e expansão da cidade, pois estes espaços verdes livres podem contribuir para a redução e o equilíbrio da temperatura, proporcionando ambientes mais agradáveis e um maior conforto térmico para toda a população.

Além da iniciativa para que esses espaços sejam legalmente constituídos, outros elementos podem ser considerados, como iniciativas e investimentos para a melhor qualificação na paisagem. Situações de convívio, melhor distribuição da vegetação e de áreas permeáveis, implantação de mecanismos de infraestruturas verdes e a própria conexão e formação de corredores verdes com os demais parques criados devem ser aspectos a serem incorporados no desenho desses espaços e nas suas relações com o entorno e com toda a cidade.

\section{CONCLUSÕES}

Por meio da análise das imagens termais do Landsat (5 e 8) foi observado um aumento da TS tanto no perímetro urbano quanto para os Parques analisados. Para a área urbana de São Carlos, houve um aumento de $1,6^{\circ} \mathrm{C}$ da TS média, de 2004 para 2020. Em ambos os anos, os picos de TS estão presentes em áreas que possuem mais espaços construídos e menos vegetação. Os Parques com vegetação mais densa (Potenciais e do Decreto) apresentaram temperatura máxima mais amena e menor amplitude térmica, podendo representar áreas importantes para a manutenção e para o equilíbrio térmico. Os Parques Existentes e os Parques Lineares, devido a supressão da vegetação e maior superfícies impermeáveis, apresentaram TS mais elevadas durante os períodos analisados.

A distribuição dos Parques e da cobertura vegetal em São Carlos deve ser feita de forma mais homogênea, não somente concentrada em algumas regiões, de modo a promover uma maior abrangência da amenização da TS em toda extensão urbana.

Destaca-se, também, a importância de uma melhor estruturação na gestão dos parques e espaços verdes em São Carlos, visando um planejamento contínuo e sistêmico, com produção e disseminação de informações para a tomada de decisões a curto, médio e longo 
prazos.

\section{AGRADECIMENTOS}

Agradecemos a colaboração e a disponibilização de informações da Secretaria Municipal de Meio Ambiente, Ciência, Tecnologia e Inovação, da Prefeitura Municipal de São Carlos, em especial ao professor José Galizia Tundisi. Agradecemos o material e o apoio fornecido por todos os integrantes do Grupo de Trabalho de Planejamento dos Parques Urbanos de São Carlos (GTPU). Agradecemos, também, o apoio para o uso de ferramentas computacionais e de geoprocessamento do Grupo de Pesquisa Geotecnologias, meio ambiente e sustentabilidade (GEOSUS) do Departamento de Ciências Ambientais, da UFSCar.

\section{REFERÊNCIAS}

ARAUJO, T. L.; DI PACE, F. T. Valores Instantâneos da Temperatura da Superfície Terrestre na Cidade de Maceió-AL Utilizando Imagens do Satélite TM/Landsat 5. Revista Brasileira de Geografia Física, Recife, v.3, n.2, p.104-111, 2010.

BERTINI, M. A.; RUFINO, R. R.; FUSHITA, A. T.; LIMA, M. I. S. Public green areas and urban environmental quality of the city of São Carlos, São Paulo, Brazil. Braz. J. Biol., São Carlos, vol.76, n.3, p.700-707, 2016.

BROWN, R. D.; VANOS, J.; KENNY, N.; LENZHOLZER, S. Designing urban parks that ameliorate the effects of climate change. Landscape and Urban Planning, Amsterdã v. 138, p.118-131, 2015.

CALLEJAS, I. J. A.; DURANTE, L. C.; OLIVEIRA, A. S.; NOGUEIRA, M. C. J. A. Uso do solo e temperatura superficial em área urbana. Mercator, Fortaleza, v. 10, n. 23, p. 207-223, 2011.

COELHO, A.L.N.; CORREA, W.S.C. (31 - 45). Temperatura de Superfície Celsius do Sensor Tirs/Landsat-8: Metodologia e Aplicações. Rev. Geogr. Acadêmica. Boa Vista, v.7, n.1, 2013.

CONGEDO, L. Semi-Automatic Classification Plugin Documentation: Release 5.0.2.1. Disponível em: <http://dx.doi.org/10.13140/RG.2.2.29474.02242/1>. Acesso em: 10/11/2020.

FEITOSA, S. M. R.; GOMES, J. M. A.; MOITA NETO, J. M.; ANDRADE, C. S. P. DE. Consequências da urbanização na vegetação e na temperatura da superfície de Teresina Piauí. REVSBAU, Piracicaba, v.6, n.2, p.58-75, 2011.

FERREIRA, L. S. Vegetação, temperatura de superfície e morfologia urbana: um retrato da região metropolitana de São Paulo. São Paulo, 2019. 195f. Tese (Doutorado em Tecnologia da Arquitetura) - Faculdade de Arquitetura e Urbanismo da Universidade de São Paulo, São Paulo, 2019.

GONÇALVES, M. P. Análise da distribuição espacial, funcionalidade e atratividade de 
áreas verdes públicas na cidade de São Carlos, SP. São Carlos, 2018, 112f. Dissertação (Mestrado em Ciências Ambientais) - Universidade Federal de São Carlos, São Carlos, 2018.

$\mathrm{HU}, \mathrm{Y}$.; JIA, G. Influence of land use change on urban heat island derived from multi-sensor data. International Journal of Climatology, Manchester, v.30, n. 9, p. 1382-1395, 2010.

IBGE - INSTITUTO BRASILEIRO DE GEOGRAFIA E ESTATÍSTICA. Informações estatísticas. 2020. Disponível em: https://cidades.ibge.gov.br/brasil/sp/sao-carlos/panorama. Acesso em 8 nov. 2020.

IPT - INSTITUTO DE PESQUISAS TECNOLÓGICAS. Mapeamento de áreas de alto e muito alto risco a deslizamentos e inundações do município de São Carlos, SP. Relatório Técnico 144.443-205. São Paulo: Gabinete do Governador, 2015.

ISAYA NDOSSI, M.; AVDAN, U. Application of Open Source Coding Technologies in the Production of Land Surface Temperature (LST) Maps from Landsat: A PyQGIS Plugin. Remote Sensing, v. 8, n.5, p. 413, 2016.

OKE, T. R; MILLS, G; CHRISTEN, A; VOOGT, J. A. Urban Climates. Cambridge: University Press. 2017.

PAVÃO, V. M.; QUERINO, C. A. S.; BENEDITTI, C. A.; PAVÃO, L. L.; QUERINO, J. K. A. da S.; MACHADO, N. G.; BIUDES, M. S. Temperatura e Albedo da Superfície por Imagens TM Landsat 5 em diferentes Usos do Solo no Sudoeste da Amazônia Brasileira. Revista Brasileira de Climatologia, Curitiba, ano 11, v. 16, 2015.

PEREIRA, C. T.; LIMA, R. S.; BOURSCHEIDT, V. Estimativa sazonal da temperatura de superfície e identificação de Ilhas de Calor Urbana na Região Portuária de Santos-SP, In: XVIII SIMPÓSIO BRASILEIRO DE SENSORIAMENTO REMOTO, Santos, SP, Anais..., 2017.

RAMPAZZO, C. R. Clima e produção do espaço urbano: contribuição ao estudo da Geografia do Clima no contexto das cidades de São Carlos e Marília. Presidente Prudente, 2015, 304f. Dissertação (mestrado). Universidade Estadual Paulista, Faculdade de Ciências e Tecnologia, 2015.

RODRIGUeS, A. P. M.; PASQUALETTO, A.; GARÇÃO, A. L. O. A influência dos parques urbanos no microclima de Goiânia. Baru, Goiânia, v. 3, n. 1, p. 25-44, 2017.

SÃO CARLOS (MUNICÍPIO). Decreto $n^{\circ} 170$, de 17 de julho de 2017. Cria os parques urbanos de proteção, lazer e educação ambiental no município e das outras providências. Diário Oficial do Município de São Carlos, São Carlos, 17 de julho de 2017.

SILVA, A. M.; SILVA, R. M. DA.; SILVA, B. B. DA. Determinação de temperatura da superfície e estimativa do saldo de radiação e evapotranspiração usando imagens LANDSAT e dados observados. Revista Brasileira de Cartografia, Rio de Janeiro, n.67/6, p. 1203-1216, 2015.

SILVA, B. A.; XAVIER, T. C.; ALVAREZ, C. E. DE. A influência da vegetação no conforto térmico para a condição microclimática de Vitória (ES). Cidades Verdes, v.03, n.08, 2015, pp. 01-15.

SPOSITO, M. E. B.; GÓES, E. M. Espaços fechados e cidades: insegurança urbana e 
fragmentação socioespacial. São Paulo: Editora Unesp, 2013.

VIANA, S.M. Percepção e quantificação das árvores na área urbana do município de São Carlos, SP. Piracicaba, 2013, 212f. Tese (Doutorado) - Escola Superior de Agricultura "Luiz de Queiroz", Universidade de São Paulo, Piracicaba, 2013.

YU, Z.; GUO, X.; JøRGENSEN, G.; VEJRE H. How can urban green spaces be planned for climate adaptation in subtropical cities? Ecological Indicators, Coimbra, v. 82, p. 152-162, 2017. 